\title{
As origens do judô brasileiro: a árvore genealógica dos medalhistas olímpicos
}

CDD. 20.ed. 796.81

900
Alexandre Velly NUNES Kátia RUBIO**

\section{Resumo}

O Brasil participou de todas as edições dos Jogos Olimpicos (J0) no judô, nos quais 12 atletas brasileiros conquistaram medalhas. 0 objetivo deste estudo foi elaborar uma "árvore genealógica judoística" do judô brasileiro a partir destes medalhistas. A metodologia utilizada foi História Oral de Vida Hibrida. Foram entrevistados os 12 medalhistas brasileiros em J0 e seus professores. Identificamos todos os formadores dos professores destes medalhistas, até encontrar os "genearcas", aqueles que chegaram ao Brasil com condições de transmitir estes conhecimentos. As informações obtidas com os entrevistados foram analisadas juntamente com outros documentos. Maeda e Satake foram os primeiros japoneses a chegar e fazer demonstrações de judô no Brasil, a partir de 1914. Ryuzo Ogawa, que fundou a Budokan em 1936, foi o genearca que influenciou o maior número destes atletas. 0 primeiro medalhista brasileiro, Chiaki Ishii, foi também um genearca, pois influenciou outros atletas e professores.

UnITERMOS: Genealogia: Judô; História oral.

\section{Introdução}

O Judô é uma modalidade esportiva de origem japonesa que chegou ao Brasil no século passado e que hoje em dia é praticado por cerca de dois milhôes de pessoas. A introdução do judô no Brasil ocorreu, principalmente, a partir dos imigrantes japoneses. Os primeiros chegaram oficialmente com Kasato Maru', em 1908. Entretanto os imigrantes japoneses vieram para o Brasil com o objetivo precípuo de fazer fortuna e retornar para sua terra natal. A prática do judô na colônia japonesa era uma das formas de manutenção de sua cultura e diversão que, somente aos poucos, foi permitida aos brasileirosnatos. Outra versão para o início dessa modalidade é a chegada dos primeiros professores-lutadores ${ }^{2}$, com o intuito de difundir esta prática no país. Dois deles, Mitsuyo Maeda e Soishiro Satake eram representantes da Kodokan ${ }^{3}$, contemporâneos em sua iniciação na escola de Jigoro Kano. Ambos chegaram ao Brasil em 14 de novembro de 1914, tendo entrado no país por Porto Alegre. Em 18 de dezembro de 1915, a trupe de lutadores chegou a Manaus, o grupo era composto ainda por Laku e Shimisu. Antes disso os lutadores rodaram o Brasil em demonstraçóes e desafios. Posteriormente Conde Koma, ou Eisei Mitsuyo Maeda radicou-se em
Belém do Pará, enquanto Satake ficou em Manaus (Asari \& Tsukamoto, 2008; Franchini \& Dornelles, 2005; Nunes, Kossmann \& SChames, 2005).

Os imigrantes japoneses continuaram chegando ao Brasil em grande número até o início da Segunda Guerra Mundial (SGM). A imigração foi interrompida por um período, tendo recomeçado alguns anos após o fim da guerra. Nas primeiras levas de imigrantes chegaram alguns dos mais importantes divulgadores do judô brasileiro, embora o motivo de sua vinda tenha sido trabalhar no país na lavoura do café e na agricultura, fazer fortuna e retornar ao Japão (CALLEJA, 1974; SAKURAI, 2007; SuZUKI, 1969; TANNo, 2008; TAKeUChI, 2007).

A forma mais comum de divulgação dos esportes de combate, neste período, eram as demonstrações e os desafios. Com isso os lutadores demonstravam a eficiência superior das suas técnicas e do seu estilo. No caso de Maeda e Satake, o estilo era o Judô Kodokan. A transformação do antigo jiu-jitsu japonês em judô, ou jiu-jitsu Kano, foi ocorrendo aos poucos. Enquanto o jiu-jitsu era ensinado majoritariamente através de um processo visual e os resultados nos combates reais eram o principal objetivo, Kano propunha um
*Escola de Educação Física, Universidade Federal do Rio Grande do Sul.

**Escola de Educação Física e Esporte, Universidade de São Paulo. 
método de ensino sistemático com princípios que buscavam o aprimoramento da sociedade (CARR, 1993; Craig, 1995; Kano, 1954, 1986, 2008b; Vinícius RUAS, comunicação pessoal, 2010).

A institucionalização da modalidade ocorreu somente após o final da segunda grande guerra. A primeira federação estadual de judô foi criada em 17 de abril de 1958, em São Paulo. A seguir vieram as federaçôes do Rio de Janeiro (09/ago/1962), Paraná (07/out/1961) e Minas Gerais (10/jun/1961). O primeiro Campeonato Brasileiro de Judô foi realizado em 1954, no Rio de Janeiro e o segundo em 1957, em Belo Horizonte, embora a Confederação Brasileira de Judô tenha sido criada somente em 1969. Antes disso, as atividades de cultura japonesa eram reguladas por uma instituição chamada Ju-kendo-Renmei, criada em 1933 e com uma "filial" paranaense, criada em 1937. Sob o comando da Ju-Kendo-Renmei, as atividades esportivas japonesas, judô, "kendô" e "yakyu" (beisebol), se desenvolveram até o início da segunda grande guerra (FederaÇÃo Mineira DE Judô, 2009; Federação Paranaense de Judô, 2009; Souza, 2010; SUZUKI, 1994; WANDERLEY, 2001).

A partir do ingresso do judô no programa olímpico, em 1964/1972, a forma de divulgação e exposição na mídia foram as participações nas competições oficiais e não mais os desafios. Paulatinamente o judô se transformou em um esporte muito praticado e com características próprias. A partir dos anos 50, o judô passou a ser a atividade de origem marcial mais conhecida, o antigo jiu-jítsu foi gradativamente perdendo espaço. Desde a criação da Kodokan, por Kano em 1882, diversas escolas de jujutsu ("ryu") aderiram ao Kodokan, inclusive no Brasil. Entretanto surgiu aqui uma nova escola, com ênfase na luta de solo e nos combates de vale-tudo, o Jiu-jítsu Brasileiro. Da mesma forma que o judô derivou das antigas escolas do jujutsu japonês, o jiu-jítsu brasileiro é uma derivação de uma escola mais antiga, o Judô ou, como era conhecido até a década de 40, Jiu-jitsu Kano (ARIMA, 1908; GRACIE, 2008; OimATSU, 1984).

Carlos Gracie e seus discípulos não aproveitaram as idéias de Jigoro Kano que defendiam a importância da formação global da pessoa e dos benefícios que a prática pode trazer para a sociedade (YoKOYAMA \& Oshima, 1915; Pfister, 1999). O enfoque principal do jiu-jítsu brasileiro sempre foi o combate real com ênfase na luta no solo. Os Gracie ainda modificaram os nomes das técnicas, "abrasileirando" algumas e criando outros termos para identificar as mesmas açôes técnicas, ensinadas nas escolas de judô Kodokan. As formas de treinar o judô, que envolvem o desenvolvimento do caráter e os seus objetivos educacionais, são consideradas uma perda de tempo pelos praticantes de jiu-jítsu brasileiro. De uma certa forma, estes aspectos educacionais vêm sendo relegados a um segundo plano, mesmo entre os praticantes de judô, quando o objetivo principal são os resultados competitivos. Alguns autores ligados ao judô competitivo ratificam a opinião dos Gracie e, pelo menos em parte, entendem que os objetivos da competição de judô não são os mesmos do judô tradicional ou da atividade física e educacional (FranCHINI \& DA Costa, 2002; Gracie \& Danaher, 2003; GeesinK, 2005; Kurihara \& Wilson, 1966; Hackney, 2009; Ohlenkamp, 2008; Otaki \& Draeger, 1983).

A ideia original deste estudo foi a de estabelecer uma genealogia a partir dos laços judoísticos dos atletas brasileiros medalhistas em Jogos Olímpicos. A elaboração de árvores genealógicas é usual em relações familiares, porém, a adaptação proposta neste estudo considerou os professores dos atletas como se fossem seus "pais" e assim sucessivamente. Utilizamos ainda um dos achados, a existência de professores formadores (P.Fo.) e professores treinadores (P.Tre.), como se fossem os dois galhos originais da árvore individual dos atletas. Assim utilizamos as figuras dos P.Fo. e P.TRE, como se fossem os pais e, desta forma, surgiram também "irmãos de judô", que são aqueles atletas formados pelos mesmos professores. Desta forma pretendemos elucidar qual a origem judoística dos atletas brasileiros medalhistas em Jogos Olímpicos e ainda qual a origem dos seus professores, identificando quais foram os primeiros professores desta prática no Brasil e qual a origem dos seus conhecimentos. A estes indivíduos denominaremos "genearcas" do judô brasileiro.

Este estudo tem por objetivo principal identificar quem foram os "genearcas do judô brasileiro" e onde se originaram os medalhistas brasileiros em Jogos Olímpicos. Desta forma, construímos uma "árvore genealógica judoística" dos 12 atletas que conquistaram medalhas até o último ciclo olímpico, Pequim-2008. A metodologia utilizada permite que a história do judô seja recontada por estes personagens, protagonistas do judô brasileiro, através de suas versōes. Os fatos históricos que já ocorreram não se alteram, entretanto, o conhecimento do passado sofre constantes alterações (BLOCH, 1945).

Este artigo é parte de um estudo mais amplo que faz parte da tese de doutorado de um dos autores junto à Universidade de São Paulo, cujo título é "A influência da imigração japonesa no desenvolvimento do judô brasileiro: uma genealogia dos atletas brasileiros medalhistas em jogos olímpicos e campeonatos mundiais." 


\section{Método}

A metodologia utilizada neste trabalho foi a Análise das Histórias de Vida, uma das formas de história oral (Meiny \& Holanda, 2010; Poirier, Clapier-Valladon \& Raybaut, 1999; Rúbio, 2006).

Os dados foram também de pesquisa histórica analítica, recorreu-se a fontes relacionadas à história e evolução do judô no Brasil. Desta forma, pode-se classificar essa metodologia como História Oral de Vida Híbrida, tendo em vista que as informações dos colaboradores foram confrontadas com outras fontes convencionais de história (Meiny, 2005; Meiny \& Holanda, 2010; Poirier, Clapier-Valladon \& Raybaut, 1999; Rubio, 2004, 2006).

\section{Definição dos colaboradores: comunidade de destino}

Os indivíduos selecionados para este estudo são os 12 atletas brasileiros que conquistaram medalhas em Jogos Olímpicos, seus professores-formadores e seus professores-treinadores. Este estudo abrange todas as participaçōes brasileiras da história. Esta investigação inicia na primeira participação brasileira neste evento, em Tóquio, 1964 e vai até os Jogos Olímpicos de Pequim, 2008. Desta forma, este estudo compreende toda a história do judô competitivo nacional em olimpíadas até a presente data.

Assume-se que esses atletas, seus professorestreinadores e os locais onde treinam ou treinaram representam a elite competitiva do judô nacional. Os professores entrevistados, que denominamos "formadores", podem ser destacados como integrantes da elite brasileira na formação de judocas. Formaram-se assim duas colônias ${ }^{4}$ distintas: a dos atletas e a dos professores. Localizamos e entrevistamos os atletas medalhistas e as pessoas que eles relataram ser, as suas maiores influências na formação e no seu treinamento quando conquistaram estas medalhas.

\section{Procedimentos}

As entrevistas com os indivíduos selecionados foram gravadas utilizando-se uma câmera marca Sony, modelo DCR-SR 45 (Handycam) e, posteriormente, transcritas parcial ou totalmente. Como equipamentos auxiliares das gravações foram utilizados, um gravador marca Olympus, modelo Pearlcorder S702 (Microcassette recorder) e um telefone celular Nokia, N95. Os mesmos equipamentos foram utilizados para as filmagens e gravações nos "dojos". As informações obtidas por meio das entrevistas com os atletas, com os professores/formadores e com os professores/treinadores que influenciaram a carreira destes atletas foram analisadas e os diversos pontos de vista foram comparados aos dados encontrados nos documentos. As observaçōes registradas e as dados históricos coletados permitiram uma triangulação dessas informações.

As entrevistas foram abertas, sem tempo determinado, porém os colaboradores eventualmente foram estimulados a dar a sua opinião com relação a determinados temas. Quando esses assuntos não eram abordados espontaneamente pelos colaboradores, o entrevistador fazia uma intervenção, estimulando-os a exporem a sua opinião.

\section{Resultados}

O Brasil conquistou 15 medalhas em Jogos Olímpicos e esses títulos são divididos por 12 atletas. Apresentamos no QUADRO 1 com os nomes dos atletas que conquistaram estas medalhas, o local de formação, o local de treinamento e os Jogos Olímpicos em que elas foram conquistadas.

Como pode ser observado no QUADRO 1, apenas uma atleta conseguiu esta façanha e, isto somente ocorreu, nos Jogos Olímpicos de Pequim. No judô, bem como em outras modalidades esportivas, as mulheres levaram muito tempo até alcançar os resultados dos homens. O naipe feminino somente ingressou no programa olímpico em Barcelona-1992, portanto vinte anos após o masculino 5 . Esta medalha reflete um crescimento recente do judô feminino no Brasil, que ocorreu a partir do século XXI e culminou com o resultado do último campeonato mundial, realizado em Paris-2011, onde o Brasil conquistou mais medalhas no naipe feminino do que entre os homens na competição individual. Neste evento as mulheres conquistaram três medalhas no individual, com Mayra Aguiar -Bronze, do Rio Grande do Sul, Sarah Menezes -Bronze, do Piauí e Rafaela SilvaPrata, do Rio de Janeiro, enquanto os homens conquistaram medalhas através de Leandro Cunha-Prata e Leandro Guilheiro ambos atletas de São Paulo. 
QUADRO 1 -Medalhistas em Jogos Olímpicos.

Fonte: Confederação BRASILEIRA DE JUDÔ, 2008; JUDOBRASIL, 2008.

\begin{tabular}{|c|c|c|c|}
\hline Nome & Formação & Treinamento & Jogos \\
\hline Walter Carmona & São Paulo/Kanayama & São Paulo/ Ishii & Los Angeles - 1984 \\
\hline Douglas Vieira & Caçapava (Sp) & São Paulo/Pinheiros & Los Angeles - 1984 \\
\hline Luiz Onmura & São Paulo/ Vila Sônia & São Paulo/São José & Los Angeles - 1984 \\
\hline Rogério Sampaio & Santos / Paulo Duarte & Santos/ABREV SC & Barcelona - 1992 \\
\hline Henrique Guimarães & Palmeiras (SP) & São Paulo / Palmeiras & Atlanta - 1996 \\
\hline Carlos Honorato & SãoPaulo / Vila Sonia & São Caetano do Sul & Sidnei - 2000 \\
\hline Leandro Guilheiro & Santos / Paulo Duarte & $\begin{array}{l}\text { Santos/Rogério Sampaio } \\
\text { São Paulo/Pinheiros }\end{array}$ & $\begin{array}{l}\text { Atenas - } 2004 \\
\text { Pequim - } 2008\end{array}$ \\
\hline Ketleyn Quadros & Brasília/SESI Taguatinga & Belo Horizonte/MTenis & Pequim - 2008 \\
\hline
\end{tabular}

A hipótese inicial de que os genearcas do judô brasileiro são todos imigrantes japoneses foi confirmada parcialmente. Os genearcas que este estudo encontrou são em sua maioria imigrantes japoneses que chegaram ao Brasil entre 1914 e 1968. Todos praticaram judô antes de chegar ao Brasil, tendo condiçōes ao chegar de transmitir esses conhecimentos. Alguns isseis, como Uichiro Umakakeba e Fuyu Oide não treinaram judô no Japão antes de imigrar ou o fizeram por pouco tempo quando eram crianças, este foi o caso do sensei Oide. Nestas situações não os considerei genearcas, pois o judô que eles ensinam ou ensinaram foi construído aqui através de outras influências. Isto não diminui a importância do seu trabalho e do legado que deixam para o desenvolvimento do judô brasileiro.

Outro grande nome do judô brasileiro, o sensei Georges Kastridget Mehdi, chegou ao Brasil muito jovem e provavelmente com algum conhecimento de judô, porém naquele momento talvez não tivesse conhecimentos suficientes para transmitir-los. Consta que praticou judô na França, antes de imigrar para o Brasil em 1951, entretanto no período da segunda guerra mundial é pouco provável que tenha conseguido treinar com Kawaishi, como consta no livro de Stanley Virgílio e no "site" da sua academia. Alguns documentos informam que Kawaishi teria lutado na SGM e, que até 1948, esteve preso na Manchúria. Ao chegar ao Brasil, em 1951, Mehdi tinha apenas 16 anos de idade. Depois disso, foi aluno de jiu-jítsu na academia Gracie no Rio de Janeiro, antes de abrir o seu próprio dojo em Ipanema. Após o Campeonato Mundial de 1965, esteve um período no Japão e lá treinou com professores de renome. Encontramos relatos de que Mehdi foi ou é amigo do lendário Isao Okano, campeão olímpico em Tóquio-1964 e uma lenda viva do judô japonês. Ao retornar ao Brasil, possivelmente ao final da década de 60 foi responsável pela formação de muitos professores e atletas. Como atleta participou dos Jogos Pan-Americanos de 1963, realizado em São Paulo e de Winnipeg em 1967, após ter se naturalizado. Conquistou medalhas em ambas as competiçôes, prata e bronze, respectivamente. No momento em que retornou do Japão, Mehdi passou a ser considerado um genearca do judô brasileiro, o único não japonês. Outro aspecto indefinido neste estudo é a naturalidade de Mehdi, enquanto alguns informam que ele nasceu na França, na região de Nice, outros informam que ele seria Argelino, portanto nascido na África ${ }^{6}$. A Argélia, porém, era possessão francesa até 1962, quando passou a ser um país independente. Assim sendo, Mehdi provavelmente tivesse cidadania francesa, mesmo que tenha nascido na África, de fato. Permanece a dúvida sobre o local, onde nasceu e onde iniciou a prática do judô (DUARTE, comunicação pessoal; GRACIE, 2000; NAGAI, comunicação pessoal, 20107; Ozon, comunicação pessoal, 2010; SuZUKI, comunicação pessoal, 2011; VIRGílIo, 2002)

A quase totalidade de imigrantes japoneses inicialmente ensinou judô na colônia japonesa. Alguns deles vieram ao Brasil como lutadores profissionais. Ao chegar participavam de desafios e demonstraçōes como forma de auferir dinheiro e também de divulgação do jiu-jitsu Kano ou jiudo, nome mais utilizado no início do século XX. Os prováveis pioneiros deste 
grupo foram Mitsuyo Maeda e Soishiro Satake, que chegaram ao Brasil em 14 de novembro de 1914. Os demais vieram inicialmente para trabalhar na lavoura cafeeira e, em função das péssimas condições encontradas migraram para outras áreas, e buscaram outras formas de ganhar a vida. A participação em desafios, demonstrações e o ensino do judô, foi uma das maneiras através das quais eles se mantinham ou complementavam sua renda. Segundo o artigo de Thomas Green e Joseph Svinth (2011), Maeda e Satake não teriam sido os primeiros professores de judô no Brasil. Este título deve pertencer a um homem chamado Miura, que teria chegado a bordo do Kasato Maru, cerca de seis anos antes da chegada de Conde Koma e sua trupe de lutadores ${ }^{8}$ (GreEn \& SvinTH, 2011; Jiudo, 1935; SouzA, 2010).

A nomenclatura do que eles ensinavam também é motivo de controvérsia. Quando a prática se referia as lutas de vale-tudo ou defesa pessoal era chamado de jiu-jitsu ou jujutsu e quando se referiam ao ensinamento das técnicas com objetivos de formação e mais adiante de competições denominavam judồ ${ }^{9}$ O termo jiu-jitsu Kano, era uma das denominaçôes encontrada até a criação das federações regionais (HANCOCK \& Higashi, 1905; Kawase, Sugihara \& Ueno, 1979).

Alguns dos professores entrevistados podem ser considerados como autodidatas, pois tiveram pouco tempo de formação com um mesmo professor e se valeram de livros e intercâmbios com outros genearcas para formar a sua própria escola ou estilo de ensinar judô. Massao Shinohara em São Paulo, Augusto de Oliveira Cordeiro no Rio de Janeiro e Uichiro Umakakeba em Bastos, são alguns exemplos. Dentre estes excepcionais professores destacamos o sensei Massao Shinohara. Nascido no Brasil e tendo praticado inicialmente kendô na colônia japonesa, iniciou por poucos dias a prática do judô, com o sensei Joji Kosakai. Este porém, retornou ao Japão, para servir seu país que havia entrado na SGM, deixando o grupo sem professor. Sendo assim, Massao seguiu na liderança do grupo e foi buscar em outras fontes, como a Budokan de Ogawa ou nos ensinamentos de Yuiti Hashizume e Sobei Tani, as condiçōes de fazer o seu grupo evoluir. Acreditamos que o sensei Shinohara pode ser considerado um autodidata no judô brasileiro, embora ele mesmo afirme que evoluiu a partir dos intercâmbios com outros professores, especialmente com a Budokan de Ryuzo Ogawa, vínculo que seu dojo mantém até hoje. Outro caso que destacaremos é o de Carlos Gracie, irmão mais velho do Clã dos Gracie, que criaram e difundiram seu estilo próprio de combate, denominado jiu-jítsu brasileiro ou jiu-jítsu Gracie. A única origem do 'brazilian jiu-jítsu' foram as aulas de Mitsuyo Maeda para Carlos Gracie. Maeda é reconhecidamente um membro da Kodokan, tendo inclusive sido graduado "post-mortem" pela Kodokan, entretanto é nosso entendimento que a família Gracie desenvolveu um método próprio de ensino e regras específicas para competição, distintas do que hoje se utiliza no judô Kodokan. Além do que, como os Gracie começaram a divulgar o seu método antes do chamado período japonês, quando a imigração trouxe alguns dos mais destacados professores do judô brasileiro, os seus discípulos se espraiaram pelo país divulgando a sua escola ("ryu”) antes do judô se consolidar. Desta forma, representantes do jiu-jítsu Gracie acabaram por contribuir para o início da prática do judô em alguns Estados brasileiros. Da mesma forma que alguns praticantes de judô migraram para o jiu-jítsu brasileiro nas décadas de 80 e 90, nos anos 50 e 60 alguns praticantes de jiu-jitsu brasileiro aproveitando o fenômeno da "esportivização" migraram para o judô e foram precursores do judô em locais onde a colonização japonesa exercia menor influência na sociedade. Por este motivo Carlos Gracie pode ser considerado como um dos genearcas do judô brasileiro, pois descendem dele alguns professores que contribuíram para a formação dos atletas brasileiros medalhistas em campeonatos mundiais e participantes de Jogos Olímpicos. De acordo com os critérios definidos pelos autores para este estudo, é possível interpretar que todos os descendentes de Carlos Gracie, são na verdade descendentes de Mitsuyo Maeda. Entretanto vamos considerar que Carlos Gracie criou um estilo próprio, nos mesmos moldes que ocorreu no Japão antigo, onde uma escola derivava de outra.

A relação nominal de genearcas não deixa dúvidas, o surgimento e a expansão do judô no Brasil estão diretamente relacionados ao processo de imigração japonesa iniciado em 1908. Considerando-se a ordem cronológica da conquista das medalhas, apresento a seguir a relação nominal dos genearcas do judô brasileiro que identificamos e, de alguma forma, se relacionam direta ou indiretamente com os atletas brasileiros medalhistas em Jogos Olímpicos ou com a formação de seus professores. 
NUNES, A.V. \& RUBIO, K.

QUADRO 2 - Genearcas do judô brasileiro de medalhistas de Jogos olímpicos.

${ }^{*}$ Cada um dos medalhistas aparece pelo menos duas vezes, sendo que a primeira apresenta a genealogia do seu professor formador e a segunda a do(s) seu(s) professor(es) treinador(es)

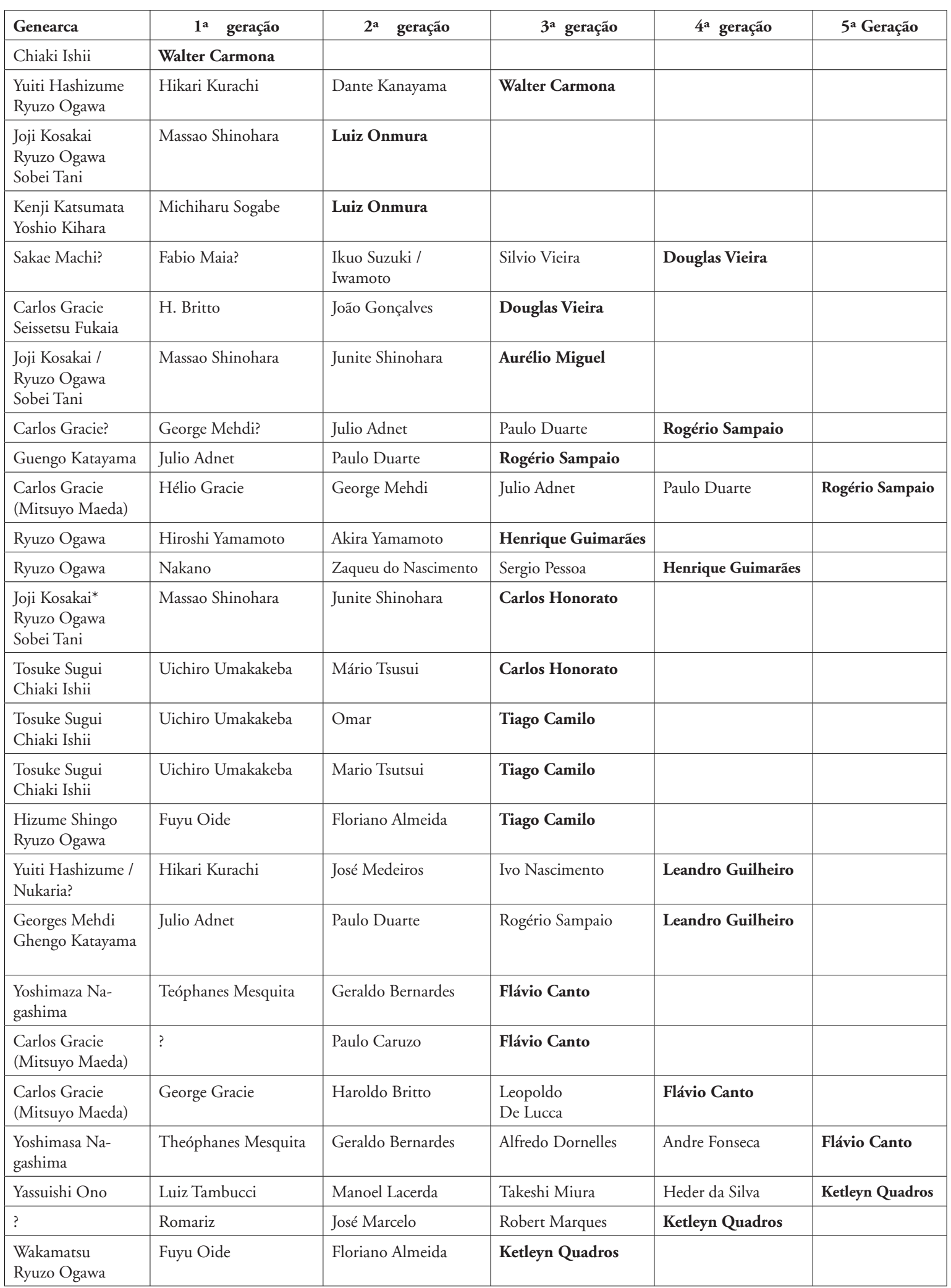

O QUADRO 2 apresenta na primeira coluna, os nomes dos genearcas e nas colunas subsequentes os seus alunos, que formaram algum dos atletas que são o principal objetivo deste estudo. O último nome de cada linha corresponde ao atleta medalhista e por este motivo, seu nome está destacado em negrito. A primeira linha do 
QUADRO, após o nome do genearca, apresenta a geração judoística da cada um dos atletas. Os imigrantes japoneses que chegaram a partir de 1908, hoje se encontram da quinta geração (go-sei), da mesma forma, o judô brasileiro também está na sua quinta geração de professores.

Analisando a primeira coluna pode-se observar a lista de genearcas que identificamos. Todos eles chegaram ao Brasil com conhecimentos suficientes para transmiti-los. A hipótese que formulamos de que todos os genearcas seriam japoneses, não se confirmou na totalidade. Entretanto dos 16 nomes que identificamos, 15 são japoneses ${ }^{10}$ e apenas um é francês, ou argelino, sensei Georges Mehdi (OzON, comunicação pessoal, $2011^{11}$ ).

\section{Discussão}

Os japoneses chegaram ao Brasil em momentos muito diferentes do desenvolvimento do judô e da história do país. Os pioneiros tiveram a sua importância na formação da primeira geração do judô brasileiro, embora no início o judô fosse praticado predominantemente por descendentes. Os "gaigoku jin" 12 nem sempre eram bem vindos aos treinamentos (ITO, 1978).

A história do judô se divide em duas eras distintas, conforme a Federação Internacional de Judô (IJF). A primeira fase seria da fundação da Kodokan até os anos 50 e a segunda fase inicia após a SGM. Na primeira fase a IJF propõe uma subdivisão, que vai da consolidação do judô no Japão até a Primeira Guerra Mundial (PGM) e a seguir o período entre os dois confrontos (InTERnational Judo Federation, 2007). Esta divisão pode ser utilizada para explicar o que ocorreu no desenvolvimento do judô no Brasil.

A primeira era de desenvolvimento do judô no Brasil também possui duas fases distintas. A primeira inicia com a chegada do Kasato Maru-1908 quando chega um imigrante de nome Miura (1909) e segue com a chegada da trupe de lutadores em novembro de 1914, Maeda, Satake, Laku e Shimisu. O trabalho de SouZA (2010) também se refere a Sakuzo Miura ou Sack Miura, porém afirma que ele não teria chegado a bordo do Kassato Maru em 1908, e sim seria náufrago de um barco pesqueiro e teria sido salvo pelo NavioEscola Brasileiro Benjamin Constant e chegou ao país em 1909 (SouZA, 2010). Neste período não haviam instituiçóes que organizassem a modalidade no país e o judô era praticado, muitas vezes com o nome jujutsu ou jiu-jitsu Kano e divulgado através de demonstrações e desafios. Possivelmente era praticado exclusivamente entre os imigrantes nas comunidades de japoneses. $\mathrm{O}$ primeiro local de treino de judô no Brasil provavelmente tenha sido no Bairro da Cachoeirinha, em Manaus, sob a tutela de Soishiro Satake. Seu trabalho teve seguimento no Clube Atlético Rio Negro também em Manaus ${ }^{13}$. Satake cuja origem judoística foi a Kodokan chegou com a trupe de Lutadores de Maeda e participou durante muitos anos de desafios e demonstraçôes. Consta que teria vencido Maeda em mais de uma ocasião, entretanto, como o principal objetivo dos desafios era angariar fundos, é possível que muitos desses resultados fossem "arranjados". Satake se estabeleceu em Manaus em 1916, segundo VIRGílio (2002) portanto, antes do final da PGM. Estes são os mais importantes registros que encontramos desta fase de desenvolvimento do judô brasileiro.

Segundo a IJF a chegada de Tatsuo Okoshi em 1924 é a primeira marca de organização do judô no Brasil. Esta informação não parece ser a mais correta, pois além de desconhecer o trabalho de Satake em sua escola no bairro da Cachoeirinha e também junto a entidades militares não faz menção às demonstrações de Maeda que são anteriores a 1924. As aulas que Maeda ministrou em Belém foram também a origem do jiu-jítsu brasileiro e, este por sua vez, deu origem a praticantes de jiu-jítsu muito antes da SGM. Alguns deles migraram para o judô em décadas posteriores. A Satake também é creditada a introdução do beisebol na Amazônia, no Atlético Rio Negro Clube. Acreditamos que a criação da Ju-Kendo-Renmei em 1933 é um marco mais importante da institucionalização do judô brasileiro, já que não encontramos evidências de que o Dr. Okoshi tenha ministrado aulas de judô entre 1924 e 1933. Após o trabalho de Satake e Maeda em Manaus e Belém, respectivamente, as primeiras academias organizadas que encontramos evidências surgiram somente na década de 30, em São Paulo com Ryuzo Ogawa (1936), Yasuishi Ono (1932), em Mogi das Cruzes com katsutoshi Naito (1931). No início da década de 30 encontramos registros da prática do judô no Estado do Paraná (1935), porém isso ocorria somente entre imigrantes nas regiões de Londrina, Assaí e Uraí. Em 1937 foi criada na região uma "filial" da Ju-Kendo-Renmei. O principal nome do judô desta região talvez seja o de Sadai Ishihara. Seu trabalho em Assaí e redondezas aconteceu sempre 
dentro das associaçōes japonesas. A presença de gaijins era rara neste período e a prática foi interrompida em 1939 em função da SGM (Liogi SuZUKI, comunicação pessoal, 2011 ${ }^{14}$; SouZA, 2010; SuZUKI, 1994).

Sob a liderança de Tatsuo Okoshi é que a Jukendo-Renmei iniciou a organizar eventos e competições até o início da SGM. Entre os pioneiros encontram-se nomes como os de: Sobei Tani em São Paulo; Katsutoshi Naito em Suzano; Shojiro Higuchi, em Mogi das Cruzes e Masami Ogino, no Rio de Janeiro. Todos estes imigrantes vieram para trabalhar na lavoura cafeeira e somente anos mais tarde é que começaram a prática do judô. Isto não deve ter ocorrido antes do início dos anos 30. Até então no Brasil ocorriam apenas demonstrações e desafios com o intuito de auferir algum dinheiro ou a prática dentro da colônia japonesa (SouzA, 2010).

Provavelmente o trabalho de Carlos Gracie no Rio de Janeiro, a partir de 1921, foi uma das únicas possibilidades de desenvolvimento do jiu-jitsu no Brasil. O jiu-jítsu Gracie formou a primeira geração de lutadores no Brasil e a partir das viagens dos irmãos, Carlos, Gastão George e Helio, influenciaram o início do jiu-jitsu em diversos Estados do país, especialmente nos locais em que a colônia japonesa não era forte. Entre 1921 e 1936 com o início da Academia de Ryuzo Ogawa em São Paulo já haviam se passado 15 anos. As competições que ocorriam neste período contavam muitas vezes com atletas oriundos da escola dos Gracie e outros da colônia japonesa, especialmente de Mogi das Cruzes e Suzano, conforme me relatou o professor Roberto Moretti (comunicação pessoal, 2009). O próprio Helio Gracie, ícone das competições de vale tudo da época, participava destes eventos. Assim alguns dos primeiros registros de aulas de jiu-jitsu antes da SGM se devem possivelmente aos irmãos Gracie e seus alunos. Notadamente em Fortaleza, onde Carlos viveu por vários anos, Recife onde eram freqüentes os desafios e competições de vale tudo, os Gracie eram a maior referência (GRACIE, 2008).

Os professores de jiu-jitsu e judô sempre estiveram vinculados as academias de polícia, marinha ou exército e ganhavam espaço entre os brasileiros. Isso ocorreu em parte pela fama adquirida pelos soldados japoneses que derrotaram os soldados russos nos combates de 1905. Depois disso os desafios e demonstrações em locais públicos, onde supostamente um menor derrotava um maior e mais forte aumentaram essa fama. Nas décadas de 30, 40 e 50 em especial no Rio de Janeiro e Fortaleza a família Gracie foi a grande responsável por esta forma de marketing.
Entre os nomes reconhecidamente vinculados ao desenvolvimento do judô brasileiro e que também participavam destes desafios estão, Takeo Yano, Yassuishi Ono, Geo Omori, além de Maeda e Satake nas décadas anteriores (JiUdO, 1935; KIMURA, 2008a; Osmar MouzinHo, comunicação pessoal, 2010 ${ }^{15}$ ).

Encontramos evidências do trabalho destes precursores na Marinha e na Brigada de Para-quedistas do Rio de Janeiro, na Polícia de Fortaleza, na Polícia de Belo Horizonte e na Academia de Polícia Militar de Natal, e também na Academia da Brigada Militar em Porto Alegre.

No período da SGM os japoneses e os demais imigrantes da região do Eixo sofreram grande discriminação e as atividades competitivas e culturais ficaram bastante prejudicadas. Após a guerra, até a criação das federações, a Ju-Kendo-Renmei tevê o papel mais importante na organização da modalidade. A primeira federação estadual foi constituída em fins dos anos 50, a Federação Paulista de Judô. Durante a década de 60 surgiram outras, no Rio de Janeiro, Paraná, e Minas Gerais, desmembrando-se da então Confederação Brasileira de Pugilismo. A Confederação brasileira de Judô surgiu somente em março de 1969, antes disso, as atividades de combate no Brasil eram dirigidas pelo Pugilismo ${ }^{16}$. Outros Estados brasileiros somente conseguiram se organizar em federações reconhecidas na década de 70 .

A primeira oportunidade de representar o Brasil em Jogos Olímpicos (Tóquio-1964), não trouxe medalhas. Embora o honroso quinto lugar de Lhofei Shiozawa deva ser considerado como um resultado excepcional. Algumas das mais importantes escolas de judô que iniciaram as suas atividades antes da SGM, encerraram as atividades e não houve solução de continuidade através de seus alunos.

O Brasil conquistou sua primeira medalha em Jogos Olímpicos em 1972 - Munich, com Chiaki Ishii. Em Munich, além de Ishii, Shiozawa participou dos jogos pela segunda vez. Somente a partir da década de 70 os atletas que representavam a Seleção Brasileira de Judô passaram a ser em sua maioria, não descendentes de japoneses $^{17}$ (JudOBRASIL, 2008; SHINOHARA, 2005).

Além dos nomes e fisionomias dos atletas denunciarem as suas origens, os "brasileiros" desta geração tinham um forte sentimento nipônico, como pode ser observado em suas muitas de suas falas. "Em nosso dojo eram só japoneses, brasileiro só tinha um..."(Fumio TANI, comunicação pessoal, 2011), ou “...quando cheguei encontrei muitos bons lutadores, Goro Saito, Kawakami, Shiozawa...tudo japonês né..." (Chiaki IsHII, comunicação pessoal, 
2010). Esta geração possuía e possui uma forte identificação com os seus antepassados, cultivando até hoje os costumes e tradições do Japão. Alguns desses descendentes mesmo sem ter ido ao Japão ainda preferem se comunicar em japonês do que em português. O sentimento de brasilidade foi crescendo de geração para geração e hoje os go-sei talvez já não cultuem tão fortemente a maneira japonesa de viver.

\section{Notas}

1. Nome do primeiro navio de imigrantes japoneses a chegar ao Porto de Santos, em 1908.

2. Em 1914 chegaram ao Brasil Mitsuyo Maeda, Soishiro Satake, Laku, Shimitsu e Okura.

3. Escola criada por Jigoro Kano para desenvolver o judô, o termo significa escola para desenvolver o caminho.

4. Colônias segundo a nomenclatura proposta por Meıry (2010) são sub-grupos da comunidade de destino. Neste estudo consideramos duas colônias, a dos atletas e a dos professores

5. O Judô entrou como esporte apresentação nos Jogos Olímpicos de Tóquio- 1964, porém em 1968 no México, não fez parte do programa. Entrou para o Programa Olímpico definitivamente em Munique-1972, apenas no masculino.

6. Comunicação pessoal - Entrevistas concedidas por: Edgard Ozon em São Paulo 25 mar. 2011; Paulo Duarte, em Cubatão 30 jun 2010 e Liogi Suzuki, em Londrina 05 set. 2011.

7. Entrevista concedida por Tadao Nagai em sua academia no Recife, em julho de 2010.

8. Comunicação pessoal recebida por mensagem eletrônica do Pesquisador Carlos Loddo de Brasília, referente ao artigo 'The circle and the octagon: Maeda's judô and Gracie’s Jiu-jitsu.

9. Vinícius Ruas Ferreira da Silva - Comunicação pessoal em entrevista concedida na região oceânica de Niterói, em 12/nov./2010.

10. A lista de Genearcas Japoneses ordenados do mais citado ao menos citado: Ryuzo Ogawa, Chiaki Ishii, Yassuishi Ono, Yoshio Kihara, Tosuke Sugui, Yuiti Hashizume, Yoshimasa Nagashima, Kenji Katsumata, Guento Katayama, Seissetsu Fukaia, Mitsuyo Maeda, Sakae Machi e Joji Kosakai.

11. Entrevista concedida em São Paulo, na sede do Esporte Clube Pinheiros em 2011.

12. Gaigoku jin ou Gaijin - Termo que se refere aos estrangeiros, no caso, os brasileiros sem ascendência japonesa.

13. Segundo comunicação pessoal do Prof. Vinícius Ruas Ferreira da Silva, que foi aluno de Satake em Manaus.

14. Entrevista concedida em Londrina em 06 de setembro de 2011.

15. Entrevista concedida por Osmar Mouzinho, sensei Biuce, último aluno vivo de Mitsuyo Maeda, em Parnamirim -Rio Grande do Norte em agosto de 2010.

16. A Confederação Brasileira de Judô foi fundada em 18 de março de 1969, porém obteve o seu reconhecimento oficial somente em 22 de fevereiro de 1972.

17. Além dos representantes brasileiros nos Jogos Olímpicos de 1964 e 1972, já citados anteriormente (Lhofei Shiozawa e Chiaki Ishii) a equipe brasileira no Campeonato Mundial Universitário de 1968, realizado em Lisboa foi composta por: Liogi Suzuki, Mateus Sugizaki, Nishimura, e apenas um brasileiro....enquanto nos Jogos Pan-americanos de 1963 a equipe era formada por, Jorge Yamashita, Lhofei Shiozawa, Milton Lovato e George Mehdi e em 1967, Akira Ono, Takeshi Miura, Lhofei Shiozawa e George Mehdi e ainda no Campeonato Panamericano de Londrina-1970, Takayuki Nishida, Mateus Sugizaki, Lhofei Shiozawa, Milton Lovato e Chiaki Ishii.

\section{Abstract}

The roots of Brazilian judo, the genealogic tree from olympic medalists

Brazil has participated in all editions of the Olympic Games (OG) in Judo, and 12 Brazilian athletes were medalists. The goal of the present study is to prepare a Judo genealogical tree from the Brazilian Judo of those medalists. The methodology used was the oral history of life hybrid. The 12 Brazilian Judo medalists and their coaches were interviewed. After identified all of the former coaches from those medalists, we were able to find the genearches, those who came into Brazil with the possibility to transmit these knowledge. The answers obtained from the respondents were analyzed together with other documents. Maeda and Satake were the first ones to arrive in Brazil and began the demonstrations, in 1914. Ryuzo 
NUNES, A.V. \& RUBIO, K.

Ogawa, who found Budokan in 1936, was the genearch who influenced the highest number of those athletes. The first Brazilian medalist, Chiaki Ishii, was a genearch as well, since he influenced other athletes and coaches.

UNITERMS: Genealogy; Judo; Oral History.

\section{Resumen}

Las orígenes del judo brasileño: el árbol genealogica de los ganadores de medallas olímpicas

Brasil ha participado en todas las ediciones de los Juegos Olímpicos (JO) en judo, aunque 12 atletas brasileños ganaron medallas. El objetivo de este estudio fue preparar un árbol genealogica judoística de estos mismos medallistas olimpicos de judo. La historia oral de vida híbrida es la metodología utilizada. Entrevistamos a los 12 medallistas brasileños y sus entrenadores. Se identificaron todos los entrenadores formadores de estos medallistas también, hasta que encuentre los genearcas, que llegaran a Brasil y lograron hacer la transmisión de este conocimiento. La información obtenida de los encuestados fueron analizadas junto con otros documentos. Maeda y Satake fueron los primeros a llegar y dar demostraciones de judo en Brasil, desde 1914. Ryuzo Ogawa, quien fundó Budokan en 1936, fue el genearca que influyó el mayor número de estos atletas. El primer medallista brasileño, Chiaki Ishii, fue también un genearca al influir otros atletas y entrenadores.

Palabras clave: Genealogía; Judo; La historia oral.

\section{Referências}

ARIMA, S. Judo: japanese physical cultura, being a further exposition of jujitsu and similar arts. Tokyo: Mifsumura, 1908. ASARI, A.Y.; TSUKAMOTO, R.Y. Da terra do sol nascente ás terras férteis do Paraná: territorialização e organização socila de nikkeys. In: SAKURAI, C. et al. (Orgs.). Resistência \& integração: 100 anos de imigração japonesa no Brasil. Rio de Janeiro: IBGE, 2008.

BLOCH, M. Apologia da historia: ou o ofício de historiador. Rio de Janeiro: Zahar, 2001.

CALLEJA, C.C. Judô. In: MACHADO, D.C. (Coord.). Manual de educação física: natação, judô. São Paulo: EPU, 1974-1979. v.10. p.51-84.

CARR, K.G. Making way: war, philosophy and sport in Japanese judo. Journal of Sport History, Los Angeles, v.20, n.2, p.167-88, 1993.

CONFEDERAÇÃO BRASILEIRA DE JUDÔ. Galeria dos campeões: medalhistas do Brasil em Campeonatos Mundiais Sênior, 2008. Disponível em: <http://www.cbj.com.br/novo/medalhistas.asp>. Acesso em: 12 nov. 2008.

CRAIG, D. Japan's ultimate martial art: jujitsu before 1882 the classical Japanese art of self-defense. Boston: Charles Tittle, 1995.

FEDERAÇÃO MINEIRA DE JUDÔ. Presidentes da Federação Mineira de Judô. Disponível em: < http://judomineiro.com.br/modules/tinycontent/index.php?id=15>. Acesso em: 7 set. 2009.

FEDERAÇÃO PARANAENSE DE JUDÔ. A história da federação. Disponível em: <http://paranajudo.org.br/ afederacao.php>. Acesso em: 7 set. 2009.

FRANCHINI, E.; DORNELES, A.G. Judô. In: Da COSTA, L.P.; MIRAGUAYA, A. Atlas do esporte no Brasil. Rio de Janeiro: Shape, 2005.

FRANCHINI, E.; Da COSTA, L.P. Fundamentos do judô aplicados a educação olímpica e ao desenvolvimento do Fair Play. In: TURINI, M.; Da COSTA, L.P. Coletânea de textos em estudos olímpicos. Rio de Janeiro: [s.ed.], 2002. p.355-72. GRACIE, R. Carlos Gracie: o criador de uma dinastia. Rio de Janeiro: Record, 2008.

GRACIE, R.; DANAHER, J. Matering jujitsu. Champaign: Human Kinetics. 2003. 
GREEN, T.; SVINTH, J.R. The circle and the octagon: Maeda's judô and Gracie's jiu-jitsu. Artigo do acervo do Pesquisador Carlos Eduardo Loddo do DF recebido por meio eletrônico em agosto de 2011.

HACKNEY, C.H. The aristotelian philosophy of the martial arts. Journal of Asian Martial Arts, [s. ed.], v.18, n.4, 2009. HANCOCK, H.I.; HIGASHI, K. The complete Kano Jiu-Jitsu (Judo). New York: Dover, 2005. Originaly published: London/NewYork: G.P. Putnam’s Sons, 1905.

INTERNATIONAL JUDO FEDERATION. Kano Jigoro (1860-1938). Disponível em: < http://www.intjudo.com/>. Acesso em: 6 dez. 2007.

. From martial art to olympic Sport. IJF News, [s. 1.], n.7, 2011. Disponível em: < http://www.intjudo.eu/magazinok/ijfnewsletter07/>. Acesso em: 25 ago. 2011.

IJF World Judo Tour 2010. IJF News, [s. 1.], n.2, 2010. Disponível em: < http://www.intjudo.eu/magazinok/ ijfnewsletter02>. Acesso em: 25 ago. 2011.

ITO, Y. Nihongo: curso elementar de Kanji. Tokyo: The Japan Foundation, 1978.

JIUDO: uma arte de cultura physica japonesa. Belém: Livraria Escolar, 1935. Obra do acervo de Vinícius Ruas Ferreira da Silva supostamente escrita por Conde Koma.

JUDOBRASIL. Resultados. Disponível em: <http://www.judobrasil.com.br>. Acesso em: 8 nov. 2008.

KANO, J. Energia mental e física: escritos do fundador do judô. Tradução Wagner Bull. São Paulo: Pensamento, 2008.

Illustrated Kodokan Judo. Tokyo: Kodansha, 1954. Tokyo: Kodansha, 1986-1989.

Judô Kodokan. Tradução Wagner Bull. São Paulo: Cultrix, 2008.

KAWASE, I.; SUGIHARA, M.; UENO, T. Nihongo: a pronúncia da lingua japonesa. Tokyo: The Japan Foundation, 1979. KIMURA, M. My judô: part 1. Disponível em: <http://www.judoinfo.com/kimura2.htm>. Acesso em: 21 nov. 2008.

My judô: part 2. Disponível em: <http://www.judoinfo.com/kimura4.htm>. Acesso em: 21 nov. 2008.

KURIHARA, T.; WILSON, H. Championship judo. Londres: Arthur Barker, 1966.

MEIHY, J.C.S.B. Manual de história oral. 5. ed. São Paulo: Loyola, 2005.

MEIHY, J.C.S.B.; HOLANDA, F. História oral: como fazer como pensar. 2. ed. São Paulo: Contexto, 2010.

NUNES, A.V.; KOSSMANN, F.T.; SCHAMES, M. Judô no Rio Grande do Sul. In: MAZO, G.Z. (Org.). Atlas do esporte no Rio Grande do Sul. Porto Alegre: [S.l.], 2005.

OHLENKAMP, N. The evolution of judo contest rules. Disponível em: http://judoinfo.com/rules2.htm. Acesso em: 12 nov. 2008

OIMATSU, S. The way of Seiryoku Zenyo - Jita kyoei and its instruction. Bulletin for the Scientific Study of kodokan Judo, Tokyo, n.6, p.3-8, 1984.

OTAKI, T:; DRAEGER, D.F.Judo formal techniques: a complete guide to Kodokan Randori no Kata. Rutland: Charles E. Tuttle, 1983. PFISTER, G. The fascination of the exotic? On the development of jujitsu and judo in Germany. In: PFISTER, G.; YUEYE, L. Sports: the east and the west. Sankt Augustin: Academia, 1999. p.29-33. Documentary volume of the 3rd International ISHPES Seminar, Shunde, Guandong, China, 16-22 sept. 1996.

POIRIER, J.; CLAPIER-VALLADON, S.; RAYBAUT, P. Histórias de vida: teoria e prática. 2. ed. Oeiras: Celta, 1999. RUBIO, K. Heróis olímpicos brasileiros: memórias, histórias e imaginário. São Paulo: Zouk, 2004.

Medalhistas olímpicos brasileiros: memórias, histórias e imaginário. São Paulo: Casa do Psicólogo, 2006.

SAKURAI, C. Os japoneses. São Paulo: Contexto, 2007.

SHINOHARA, M. Manual de Judô Shinohara. 5. ed. São Paulo: [s.n.], 2005.

SOUZA, G.B. Princípios e valorização do judô na vida cotidiana de mestres da região de Mogi das Cruzes. São Paulo, 2010. Dissertação (Mestrado) - Escola de Educação Física e Esporte, Universidade de São Paulo, São Paulo, 2010. SUZUKI, L. A história do judô no Paraná. 1994. Dissertação (Mestrado em Educação Física) - Universidade de Ribeirão Preto, Ribeirão Preto, 1994. Disponível em: <http:/ /www.paranajudo.org.br/destaque.php?id=42>. Acesso em: 11 ago. 2011.

SUZUKI, T. The Japanese immigrant in Brazil: narrative part. Tokyo: University of Tokyo, 1969.

TANNO, J.L. Formas de sociabilidade e inserção de imigrantes japoneses e seus descentes na sociedade paulista, 19301970. In: HASHIMOTO, F. (Org.). Cem anos da Imigração Japonesa. São Paulo: UNESP, 2008. p.63-77.

TAKEUCHI, M.Y. Japoneses: a saga do povo do sol nascente. São Paulo: Nacional, 2007.

VIRGÍLIO, S. Personagens e histórias do judô brasileiro. Campinas: Átomo, 2002.

WANDERLEY, P.F.T. O judo no Rio de Janeiro: orígem e trajetória. Material em arquivo eletrônico obtido com o Prof. Rudolf Otero Hermany durante entrevista no Rio de Janeiro em 2010. http:/ /pt.scribd.com/doc/61487416/HISTORICODO-JUDO-NO-RIO-DE-JANEIRO. 
NUNES, A.V. \& RUBIO, K.

YOKOYAMA, S.; OSHIMA, E. Judo: judô kyohan. Tradução Yamakichi Horiguchi Nishodo. Tokyo: [s.n.], 1915.

\begin{tabular}{r|l} 
ENDEREÇO & \\
Alexandre Velly Nunes & Recebido para publicação: 10/10/2011 \\
R.Jacinto Osório, 150 apto. 1002 & Revisado: 14/05/2012 \\
e-mail: alexandre.nunes@ufrgs.br & Aceito: 25/05/2012 \\
90040-290 - Porto Alegre - RS - BRASIL &
\end{tabular}

678 • Rev. bras. Educ. Fís. Esporte, São Paulo, v.26, n.4, p.667-78, out./dez. 2012 